\title{
APLIKASI SISTEM INFORMASI AKUMULASI PENYUSUTAN BARANG INVENTARIS PADA AMIK TRI DHARMA PEKANBARU
}

\author{
Catriwati ${ }^{1}$, Suwarti ${ }^{2}$ \\ ${ }^{1}$ Amik Mahaputra Riau, ${ }^{2}$ AMIK Tri Dharma Pekanbaru \\ ${ }^{1}$ JL. Lili Satu NO. 74-B Sukajadi Pekanbaru, ${ }^{2}$ Jalan Jendral Sudirman No. 68, Pekanbaru - Riau \\ Email: suwarty.atd87@gmail.com ${ }^{1}$, catriwati.wati@gmail.com ${ }^{2}$
}

\begin{abstract}
ABSTRAK
Penghitungan inventaris sangat berpengaruh terhadap proses operasional dalam perusahaan. Terkadang masalah ditimbulkan dari perhitungan inventaris yang tidak teliti atau terjadi miss kesalahan perhitungan) menyebabkan perusahaan tidak dapat meningkatkan taraf atau level dari perusahaannya, serta menyebabkan terjadinya kecelakaan dalam suatu proses pekerjaan. Sistem Informasi Akumulasi Penyusutan ini merupakan sebuah sistem yang dirancang untuk membantu proses perhitungan inventarisasi pada AMIK Tri Dharma Pekanbaru, walaupun sebenarnya sistem yang selama ini telah digunakan pada AMIK Tri Dharma Pekanbaru telah terarah, tetapi dalam penggunaannya sering terjadi kesalahan-kesalahan dalam perhitungan inventarisnya, sehingga kesalahan tersebut mempengaruhi kepada laporan keuangan dari AMIK Tri Dharma Pekanbaru. Dengan adanya aplikasi ini proses perhitungan invetarisasi menjadi lebih efisien dan dapat meminimalisir kesalahan-kesalahan yang sering terjadi pada perusahaan.
\end{abstract}

Kata Kunci : Sistem Informasi, Akumulasi Penyusutan, Inventaris

\section{ABSTRACT}

Inventory calculation greatly influences the operational processes in the company. Sometimes problems arising from inventory calculations that are not accurate or miscalculated miss occur) cause the company can not improve the level or level of the company, and cause accidents in a work process. This Depreciation Accumulation Information System is a system designed to assist the inventory process in the AMIK Tri Dharma Pekanbaru, even though the system that has been used in the AMIK Tri Dharma Pekanbaru has been directed, but in its use errors often occur in the calculation of inventory, so these errors affect the financial statements of AMIK Tri Dharma Pekanbaru. With this application the inventory calculation process becomes more efficient and can minimize errors that often occur in the company.

Keywords: Information Systems, Accumulated Depreciation, Inventory

\section{PENDAHULUAN}

Dalam proses perkembangan teknologi informasi di dalam kehidupan suatu kampus maupun masyarakat pribadi diperlukannya penyesuaian posisi akan perubahan teknologi yang berubah-ubah setiap saat. Penyesuaian yang sesuai terhadap teknologi informasi akan berpengaruh pada proses pengolahan data informasi di kampus, dimana hal ini juga berpengaruh kepada dunia pendidikan.

Dalam dunia pendidikan seperti pada AMIK Tri Dharma Pekanbaru, penghitungan inventaris sangat berpengaruh terhadap proses operasional dalam kampus. Terkadang masalah ditimbulkan dari perhitungan inventaris yang tidak teliti atau terjadi nya miss calculation (kesalahan perhitungan) menyebabkan AMIK Tri Dharma Pekanbaru tidak dapat meningkatkan taraf atau level dari kampusnya, serta menyebabkan terjadinya kecelakaan dalam suatu proses pekerjaan kampus.

Masih digunakannya sistem pembukuan dalam perhitungan akumulasi penyusutan inventaris pada AMIK Tri Dharma Pekanbaru menyebabkan sering terjadinya kesalahan atau keterlambatan dalam perhitungan penyusutan itu sendiri. Terkadang dengan penggunaan sistem pembukuan , 
eISSN : 2580-3042

pISSN : 1979-0694

kampus kesulitan untuk merawat atau memperhatikan inventarisnya, keamanan dalam penyimpanan data informasi inventaris secara pembukuan juga sangat jauh dari kata aman. Dengan adanya sistem komputerisasi atau pembuatan sistem informasi akumulasi penyusutan barang inventaris, kampus dapat menghitung inventarisnya secara cepat dan lebih akurat, kampus juga dapat meningkatkan taraf atau level kampus serta dapat merawat dan memperhatikan inventarisnya, keamanan dan kerahasian data inventaris yang dimiliki oleh kampus juga akan lebih aman.

Menurut (Ikatan Akuntan Indonesia, 2009) Beban penyusutan harus diakui dalam laporan laba rugi, kecuali bab lain mensyaratkan biaya tersebut merupakan bagian biaya perolehan suatu aset. Misalnya, penyusutan aset tetap manufaktur termasuk biaya persediaan.

Penyusutan dimulai ketika suatu aset tersedia untuk digunakan, misalnya aset berada di lokasi dan kondisi yang diperlukan sehingga mampu beroperasi sebagaimana maksud manajemen. Penyusutan dihentikan ketika aset dihentikan pengakuannya. Penyusutan tidak dihentikan ketika aset digunakan atau dihentikan penggunaan aktifnya, kecuali aset tersebut telah disusutkan secara penuh. Namun, dalam metode penyusutan berdasar penggunaan ( usage method of depreciation), beban penyusutan menjadi nol ketika tidak ada produksi (Ikatan Akuntan Indonesia, 2009).

Menurut (PP No. 27 2014, 2014)
"Inventarisasi melakukan pendataan, pencatatan, dan pelaporan hasil pendataan Barang Milik Negara / Daerah". Dari beberapa pengertian tersebut dapat disimpulkan bahwa Inventarisasi Aset merupakan serangkaian kegiatan untuk melakukan pencatatan, pengamanan, pendokumentasian \& pelaporan hasil pencatatan kepemilikan suatu aset.

Ada dua jenis barang yang harus diinventarisasi menurut (Rizki, 2018) yaitu:

1. Aset berwujud atau tangible assets adalah

Kekayaan yang dapat dimanifestasikan secara fisik dengan menggunakkan panca indera.

Contoh aset berwujud antara lain berupa :

a. Tanah atau lahan;

b. Bangunan;

c. Infrastruktur misal jalan raya, jembatan, irigasi, waduk;

d. Peralatan dan perlengkapan pabrik atau plant and machinery;

e. Peralatan dan perlengkapan kantor misalnya meubel atau furniture;

f. Persediaan barang;

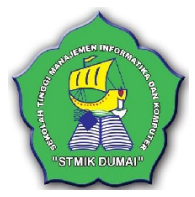

g. Sumberdaya alam seperti bahan tambang,hutan/tanaman,air dan sumberdaya alam lainnya.

2. Aset tidak berwujud atau Intangible Assets adalah kekayaan yang manifestasinya tidak berwujud secara fisik yakni tidak dapat disentuh, dilihat, atau tidak bisa diukur aecara fisik, namun kekayaan ini memberikan manfaat serta memiliki nilai tertentu secra ekonomi sebagai hasil dari proses usaha atau melalui waktu. Aset ini antara lain berupa :

a. Hak paten misal untuk sebuah formulasi produk;

b. Hak cipta atau copyright atau sebuah karya;

c. Nama baik sebuah organisasi/perusahaan atau Goodwill;

d. Hak merek dagang;

e. Hak atas usaha waralaba atau franchise.

Menurut (Fatkhudin, 2016), inventarisasi merupakan pengelolaan barang milik daerah pada dasarnya berhubungan dengan menajemen materi dan manajemen perlengkapan daerah. Manajemen materi adalah proses kegiatan perencanaan kebutuhan pemilihan sumber, pembelian, pemindahan, penyimpanan dan pengawasan materil/produksi dalam rangka meningkatkan keuntungan perusahaan.

Selanjutnya menurut (Rizki, 2018), Inventaris adalah seluruh barang yang dimiliki oleh Pemerintah Daerah yang penggunaanya lebih dari satu tahun dan di catat serta didaftarkan dalam buku inventaris.Pengelolaan inventaris berpengaruh terhadap semua fungsi sistem operasi. Selayaknya proses manajerial, inventaris sangat diperlukan dalam serangkaian proses perencanaan hingga penghapusan suatu barang inventaris. Perencanaan inventaris berperan penting dalam kegiatan manajerial suatu instansi.Berkaitan dengan aktivitas pembekalan, inventaris dipahami sebagai pencatatan selengkapnya mengenai barang-barang perkantoran yang telah dibeli, diterima, dibagikan dan dipakai pada seluruh komponen organisasi, baik mengenai barang tahan lama maupun habis pakai.

Menurut (Fajarianto, Iqbal, \& Sanjaya, 2018), aplikasi adalah penggunaan dalam suatu perangkat komputer, instruksi (instruction) atau pernyataan (statement) yang disusun hingga sedemikian rupa komputer dapat memproses masukan (input) menjadi keluaran (output).

Menurut (Maulana, Sadikin, \& Izzudin, 2018), Sistem merupakan suatu kumpulan atau kesatuan dari jaringan kerja dari prosedur-prosedur yang saling berhubungan, elemen-elemen yang saling 
eISSN : 2580-3042

pISSN : 1979-0694

berkaitan untuk mencapai suatu tujuan tertentu. Sedangkan menurut (Sutabri, 2012), informasi adalah data yang telah diklasifikasikan atau diolah atau diinterpretasikan untuk digunakan dalam proses pengambilan keputusan.

Definisi informasi merupakan hasil dari pengolahan data yang menggambarkan suatu kejadian-kejadian nyata yang dapat digunakan sebagai alat bantu dalam pengambilan suatu keputusan (Sidik, Mariana, \& Anggraeny, 2018). Sedangkan Sistem informasi dapat didefinisikan secara teknis sebagai serangkaian komponen yang saling berhubungan yang mengumpulkan atau mendapatkan, memproses, menyimpan, dan mendistribusikan informasi untuk mendukung pengambilan keputusan, koordinasi, pengawasan di dalam sebuah organisasi (Hernandhi Tri, 2018).

Penelitian sebelumnya menjelaskan bahwa sistem invetarisasi dapat memudahkan dalam pengolahan data laporan nilai ekonomis yang sesuai dengan standar akuntansi keuangan. Selain itu dapat membantu dalam mengefektifkan waktu untuk menghasilkan informasi secara akurat dan tepat (Purba, 2018).

\section{METODOLOGI PENELITIAN}

Penelitian ini dilakukan dan dapat diselesaikan melalui lima tahapan penelitian sebagaimana tertuang pada gambar 1 yaitu (1) analisis kebutuhan dan pengumpulan data, (2) perancangan sistem, (3) perancangan aplikasi/program, (4) implementasi dan pengujian sistem serta analisis hasil pengujian, dan yang terakhir adalah (5) penulisan laporan hasil penelitian.

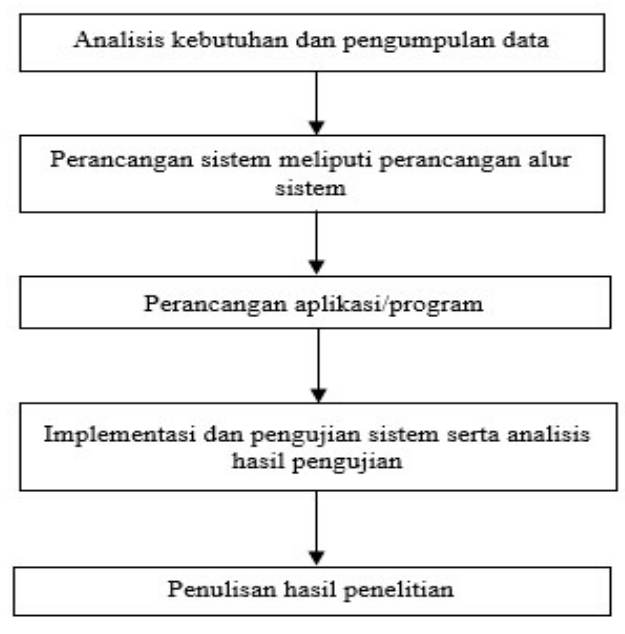

Gambar 1. Iahap Penelıtian

Dalam penelitian ini bertujuan untuk lebih memahami bagaimana cara yang tepat untuk menganalisa dan merancang aplikasi sistem informasi akumulasi penyusutan barang inventaris

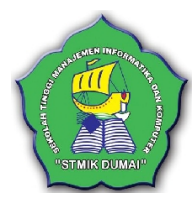

dengan menggunakan metode garis tetap atas nilai buku secara menurun.

\section{HASIL DAN PEMBAHASAN}

Berdasarkan analisa dan perancangan input maupun output sistem yang sudah dilakukan pada sistem informasi akumulasi penyusutan barang inventaris, maka hasil dari rancangan aplikasi akumulasi penyusutan batrang inventaris tersebut dapat diimplementasikan seperti berikut ini:

Pada Form Login ini adalah pintu keluar masuknya user kedalam sistem yang sudah dirancang. Fungsi dari login ini adalah sebagai otorisasi (pembagian hak akses) untuk user siapa saja yang telah diberi hak akses. Bentuk dari Form Login adalah sebagai berikut :

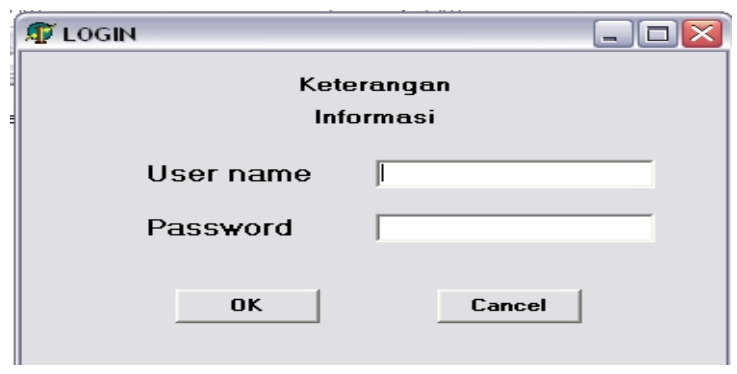

Gambar 2. Tampilan Login

Pada Menu Utama seperti yang sudah dijelaskan pada bab sebelumnya bahwa pada menu utama ini adalah tempat dimana user akan dihubungkan dengan sub - sub menu (anak menu) lainnya sesuai dengan sub menu apa yang akan digunakan.

Gambar 3 merupakan design dari Menu Utama dari sistem informasi akumulasi penyusutan barang inventaris pada AMIK Tri Dharma Pekanbaru tersebut :

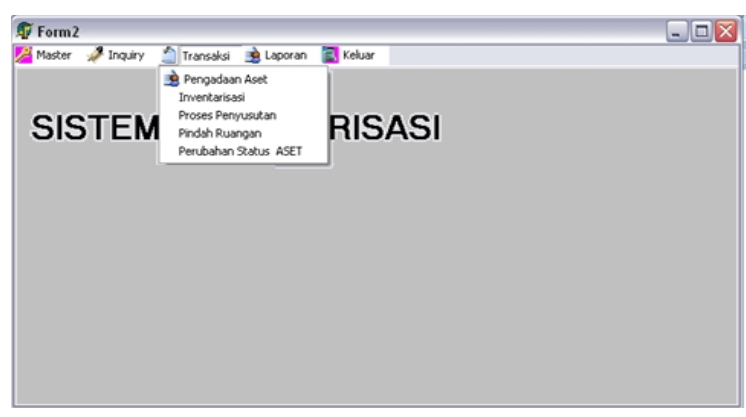

Gambar 3. Tampilan Menu utama

Pada sub menu data barang ini adalah menu yang digunakan untuk menambahkan, menghapus atau mengubah data barang yang akan 
I N F O R M A I K A

Jurnal Informatika, Manajemen dan Komputer, Vol. 11 No. 1 , Mei 2019

eISSN : 2580-3042

pISSN : 1979-0694

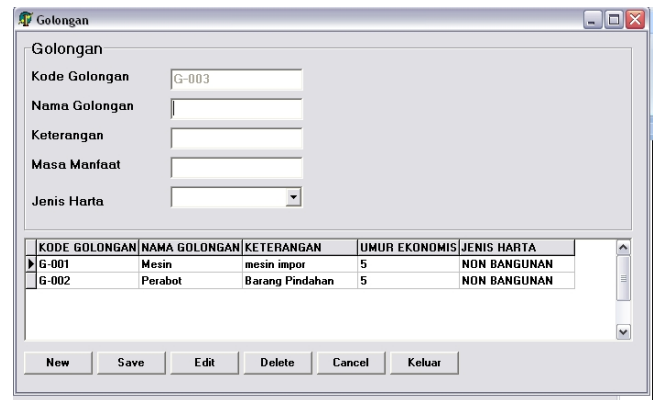

Gambar10. Tampilan Input Data Golongan

Form ruangan merupakan form yang berfungsi sebagai pembuatan kode ruangan. Dalam form ini tersedia tombol untuk menghapus atau mengubah serta menambah ruangan seperti diperlihatkan pada gambar 11 :

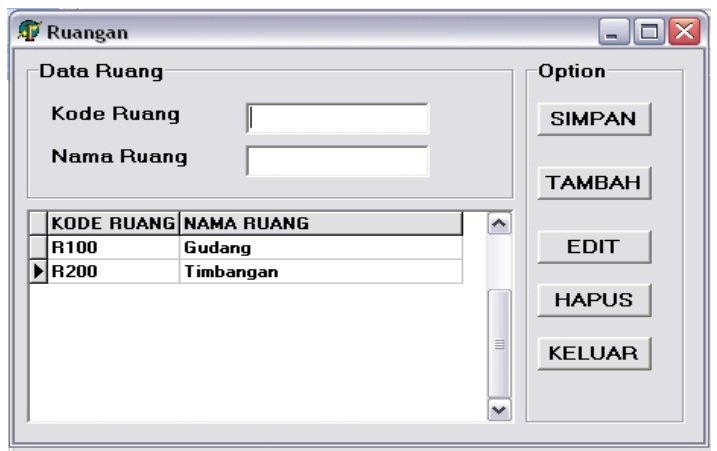

Gambar 11. Tampilan Input Data Ruangan

Merupakan laporan data barang yang ada dalam perusahaan seperti diperlihatkan pada gambar 12 :

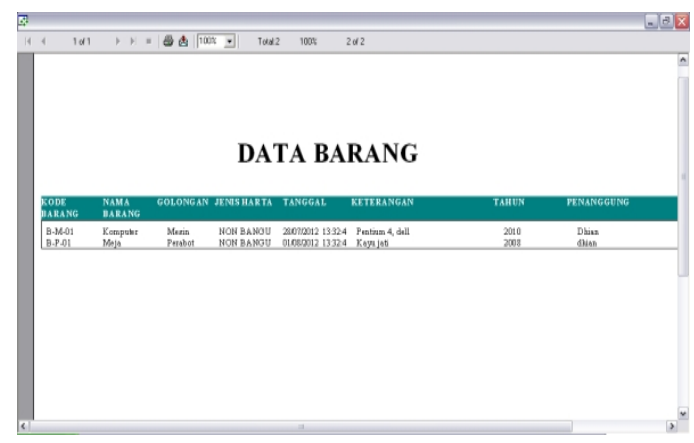

Gambar 12. Laporan Barang

Merupakan laporan dari pengadaan yang terjadi didalam proses inventaris barang seperti diperlihatkan pada gambar 12 :

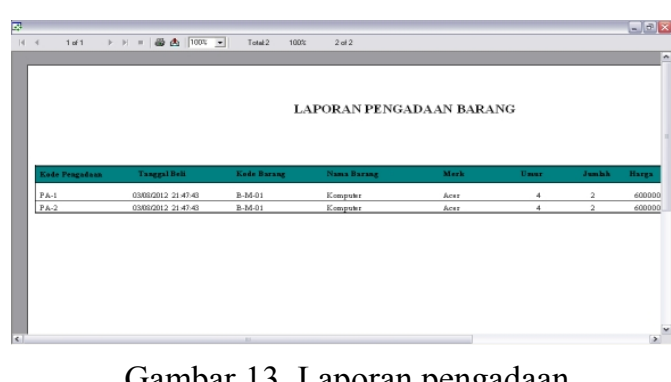

Gambar 13. Laporan pengadaan

Berisi laporan penyusutan dari masing-masing barang seperti diperlihatkan pada gambar 14 :

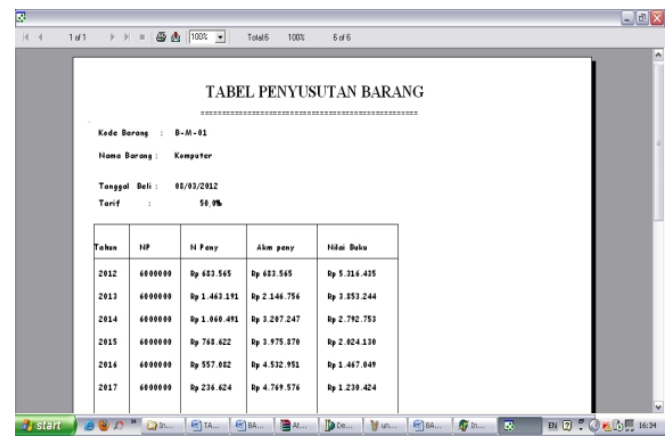

Gambar 14. Laporan Penyusutan

\section{KESIMPULAN}

Aplikasi Sistem Informasi Akumulasi Penyusutan ini merupakan sebuah sistem yang dirancang untuk membantu proses perhitungan inventarisasi pada AMIK Tri Dharma Pekanbaru, walaupun sebenarnya sistem yang selama ini telah digunakan telah terarah, tetapi dalam penggunaannya sering terjadi kesalahan-kesalahan dalam perhitungan inventarisnya, sehingga kesalahan tersebut mempengaruhi kepada laporan keuangan.

Untuk meminimalisirkan kesalahankesalahan yang sering terjadi dalam proses perhitungan inventarisasi barang perusahaan, maka penulis memberikan beberapa saran diantaranya sebelum dilakukan penerapan dari sistem baru ini, agar dilakukan training (pelatihan) kepada pemakai, agar mengetahui bagaimana sistem ini bekerja. Agar terhindar dari kesalahan proses data, sebaiknya dilakukan percobaan dan evaluasi sistem sebelum sistem baru ini diimplementasikan terhadap data sebenarnya.

\section{REFERENSI}

Fajarianto, O., Iqbal, M., \& Sanjaya, H. (2018). Perancangan Aplikasi Untuk Mengecek Perbedaan Lot Barang Ekspor Study Kasus Di PT Victory Chingluh Indonesia. "Perancangan Adalah Proses Pengembangan Spesifikasi Baru Berdasarkan 
Rekomendasi Hasil Analisis Sistem"[4]. Sugianto Menjelaskan "Perancangan Adalah Suatu Kegiatan Membuat Desain Teknis Berdasarkan Kegiatan Pada Waktu Proses Analisa"[5]., 8(1).

Fatkhudin, A. (2016). Sistem Administrasi Kependudukan dan Inventarisasi Desa Kulu Kabupaten Pekalongan. Ilmu Komputer, Vol. 2, No. 1, April 2016, 2(1), 7-11.

Hernandhi Tri, D. (2018). Desain Sistem Informasi Pemasaran Berbasis Website Untuk Promosi ( Studi Kasus pada Kedai Ayam Geprak \& Sambal Bawang Malang ). Jurnal Administrasi Bisnis, 55(1), 1-10.

Ikatan Akuntan Indonesia. (2009). Standar Akuntansi Keuangan (SAK): Entitas Tanpa Akuntabilitas Publik (ETAP).

Maulana, A., Sadikin, M., \& Izzudin, A. (2018). Implementasi Sistem Informasi Manajemen Inventaris Berbasis Web Di Pusat Teknologi Informasi Dan Komunikasi - BPPT. SETRUM Sistem Kendali-TenagaElektronika-Telekomunikasi-Komputer, 7(1), 182-196.

PP No. 27 2014. (2014). Inventarisasi.

Purba. (2018). Sistem Informasi Inventarisasi Aktiva Tetap Pada Universitas Methodist Indonesia, 1, 89-92.

Rizki, F. (2018). Prosedur Pengelolaan dan Pemeliharaan Layout serta Barang Inventaris di Fakultas Ekonomi dan Bisnis Universitas Sumatera Utara.

Sidik, A., Mariana, A. R., \& Anggraeny, A. R. (2018). Perancangan Sistem Informasi E Recruitment Guru Studi Kasus di SMK Kusuma Bangsa, 8(1), 69-74.

Sutabri, T. (2012). Konsep Sistem Informasi. 